\title{
Aches and pains with a shocking rash
}

\author{
Anila Chacko MBBS DCh MD ${ }^{1}$, Sanjay Mahant MD MSc FRCPC ${ }^{2}$, \\ Astrid Petrich PhD D(ABMM) $)^{3}$, Anupma Wadhwa MD MEd FRCPC ${ }^{1}$
}

\section{CASE PRESENTATION}

A 10-year-old girl presented to the emergency department with a three-day history of fever and generalized rash. Eleven days earlier, she had been camping in Ontario. Activities while camping included sleeping in a tent, hiking in the forest and swimming in a lake. She sustained multiple mosquito bites that were pruritic and subsequently formed scabs. Ten days before presentation, she developed left hip and thigh pain, which progressed in severity over the next three days. She also developed severe generalized myalgia. Three days before presentation she developed a fever and an erythematous, nonpruritic rash. The rash was first noticed on the thigh but soon involved the upper limbs, palms and soles. There was no sore throat or contact with others with fever or rash. Her general practitioner suspected scarlet fever and she was started on amoxicillin. After no improvement over the following day, she presented to the emergency room.

On examination in the emergency department, the patient was febrile and her blood pressure was $100 / 50 \mathrm{mmHg}$. She had a generalized erythematous macular rash, bilateral injected conjunctiva, jaundice, peeling of the skin on the soles of her feet and multiple hyperpigmented crusted lesions on her legs. She had generalized myalgia with tenderness in the left hip and thigh region. Over the subsequent $6 \mathrm{~h}$ to $12 \mathrm{~h}$, her blood pressure dropped to $85 / 37 \mathrm{mmHg}$ and she had a peak temperature of $39.2^{\circ} \mathrm{C}$. She was treated with fluid resuscitation and antimicrobials.

Her white blood cell count was $40.4 \times 10^{9} / \mathrm{L}$ with a left shift and her platelet count was $72 \times 10^{9} / \mathrm{L}$. She was in renal failure (serum creatinine level $400 \mu \mathrm{mol} / \mathrm{L}$ ) and had conjugated hyperbilirubinemia (serum conjugated bilirubin level $138 \mu \mathrm{mol} / \mathrm{L}$ ) and mild transaminitis (alanine aminotransferase level $157 \mathrm{U} / \mathrm{L}$, aspartate aminotransferase level $264 \mathrm{U} / \mathrm{L}$ ). Ultrasound of the left hip showed no joint effusion. $\mathrm{X}$-rays of the femur and lumbosacral spine were unremarkable.

What is the diagnosis?

\section{DIAGNOSIS}

At admission, on account of her camping exposure history and her presentation with shock, jaundice, macular rash, acute renal failure and scabbed skin lesions, the differential diagnosis included bacterial sepsis (group A streptococcus, Staphylococcus aureus), leptospirosis, rickettsial infections, other tickborne illnesses (babesia, ehrlichiosis, anaplasmosis) and hantavirus. She was empirically started on vancomycin, ceftriaxone and doxycycline.

On the fourth hospital day, her admission blood culture grew methicillin-sensitive $S$ aureus. The antibiotics were changed to cefazolin and clindamycin. The polymerase chain reaction (PCR)/serology investigations for the other potential infections were subsequently negative.

A magnetic resonance imaging scan of the pelvis obtained on the fourth day of hospitalization revealed a multilobular fluid collection extending from the sacroiliac joint involving the psoas muscle, consistent with sacroiliitis and psoas abscess. There was abnormal T2 hyperintensity and T1 hypointensity in the adjacent sacral and iliac bone marrow suggestive of osteomyelitis. The hip joints were unremarkable. A contrast study was not performed due to renal failure.

The clinical presentation and imaging were consistent with pelvic (sacroiliac) osteomyelitis. In addition, she fulfilled the Centers for Disease Control and Prevention (Georgia, USA) criteria for a confirmed case of toxic shock syndrome (TSS) (Table 1) (1). Desquamation of her hands and feet progressed in the second week of admission. Her renal and liver parameters returned to normal with supportive care. Her psoas abscess resolved radiographically and her pain improved clinically after antibiotic treatment for subacute pelvic osteomyelitis.

PCR for staphylococcal toxins was performed at the National Microbiology Laboratory in Manitoba. The TSS toxin-1 (TSST-1) PCR was negative. Staphylococcus enterotoxins C, G and I, however, were positive.

\section{DISCUSSION}

Staphylococcal TSS is an acute multisystem disease that is characterized by fever, hypotension, rash and desquamation on hands and feet, with evidence of $\geq 3$ organ systems involved. TSS associated with staphylococci was first described in 1978 (2) and is classified as either menstrual or nonmenstrual. After an initial epidemic of menstrual TSS in 1980 in the United States, the overall incidence has declined to 0.5 per 100,000 population. This has been attributed to public education and the discontinuation of high-absorbency tampons. Currently, nonmenstrual TSS accounts for $50 \%$ of all reported cases and has a marked female predilection. The median age of children with nonmenstrual TSS is 9.5 years $(3,4)$.

In TSS, bacterial toxins act as superantigens that directly activate $\mathrm{T}$ cells. This leads to an overwhelming release of cytokines, causing the manifestations of TSS. The most common Staphylococcus toxin for both menstrual and nonmenstrual TSS is TSST-1 (1-3). The next most common toxins in nonmenstrual TSS are enterotoxins A, B and C (5).

The staphylococcal toxins identified in our patient were enterotoxin C, G and I. While enterotoxin C has been reported as the third most common toxin causing nonmenstrual TSS, enterotoxins G and I are less common. The first time enterotoxin $\mathrm{G}$ and I were reported as being linked to TSS was in 1999 (6). This article described S aureus strains isolated from nine patients with TSS who were all positive for both enterotoxin G and I by PCR. None of the cases were positive for the other known superantigenic toxins (TSST-1, Staphylococcus enterotoxin $\mathrm{A}$ to $\mathrm{E}$ and $\mathrm{H}$ ), thus supporting the argument that enterotoxin $\mathrm{G}$ and I are toxins that can also lead to TSS.

The primary site of our patient's $S$ aureus infection was pelvic osteomyelitis. Pelvic osteomyelitis, the fourth most common site of

${ }^{1}$ Division of Infectious Diseases, The Hospital for Sick Children; ${ }^{2}$ Division of Pediatric Medicine, The Hospital for Sick Children; Department of Pediatrics, University of Toronto; ${ }^{3}$ Department of Paediatric Laboratory Medicine, The Hospital for Sick Children; Department of Pathology and Laboratory Medicine, University of Toronto, Toronto, Ontario

Correspondence: Dr Anupma Wadhwa, Division of Infectious Diseases, Hospital for Sick Children, 555 University Avenue, Toronto, Ontario M5G 1X8. Telephone 416 813-7654 ext 202676, e-mail anupma.wadhwa@sickkids.ca 
TABLE 1

Centers for Disease Control and Prevention (Georgia, USA) clinical case definition for staphylococcal toxic shock syndrome* and criteria fulfilled by the patient

\begin{tabular}{|c|c|}
\hline Clinical criteria & $\begin{array}{l}\text { Criteria fulfilled by } \\
\text { the patient }\end{array}$ \\
\hline Fever: temperature $\geq 102.0^{\circ} \mathrm{F}\left(\geq 38.9^{\circ} \mathrm{C}\right)$ & $\checkmark$ \\
\hline Rash: diffuse macular erythroderma & $\checkmark$ \\
\hline Desquamation: 1-2 weeks after onset of illness, particularly involving the palms and soles & $\checkmark$ \\
\hline \multicolumn{2}{|l|}{ Hypotension: } \\
\hline $\begin{array}{l}\text { Systolic blood pressure } \leq 90 \mathrm{mmHg} \text { for adults or }<5 \text { th percentile according to age for children }<16 \text { years of age; orthostatic drop in } \\
\text { diastolic blood pressure } \geq 15 \mathrm{mmHg}\end{array}$ & $\checkmark$ \\
\hline \multicolumn{2}{|l|}{ Orthostatic syncope or dizziness } \\
\hline \multicolumn{2}{|l|}{ Multisystem involvement ( $\geq 3$ of the following organ systems): } \\
\hline \multicolumn{2}{|l|}{ Gastrointestinal: Vomiting or diarrhea at onset of illness } \\
\hline Muscular: Severe myalgia or creatine phosphokinase level $\geq 2$ times the upper limit of normal & $\checkmark$ \\
\hline Mucous membrane: Vaginal, oropharyngeal or conjunctival hyperemia & $\checkmark$ \\
\hline $\begin{array}{l}\text { Renal: Blood urea nitrogen or creatinine } \geq 2 \text { times the normal upper limit, or pyuria ( } \geq 5 \text { leukocytes per high-power field) in the absence of } \\
\text { urinary tract infection }\end{array}$ & $\checkmark$ \\
\hline Hepatic: Total bilirubin, alanine aminotransferase enzyme or asparate aminotransferase enzyme levels $\geq 2$ times the upper limit of normal & $\checkmark$ \\
\hline Hematological: Platelets $<100,000 / \mathrm{mm}^{3}$ & $\checkmark$ \\
\hline \multicolumn{2}{|l|}{$\begin{array}{l}\text { Central nervous system: Disorientation or alterations in consciousness without focal neurologic signs when fever and hypotension are } \\
\text { absent }\end{array}$} \\
\hline \multicolumn{2}{|l|}{ Laboratory criteria } \\
\hline \multicolumn{2}{|l|}{ Negative results on the following tests, if obtained: } \\
\hline Blood, throat or cerebrospinal fluid cultures (blood culture may be positive for Staphylococcus aureus) & $\checkmark$ \\
\hline Negative serologies for Rocky Mountain spotted fever, leptospirosis or measles & $\checkmark$ \\
\hline
\end{tabular}

TABLE 2

Osteomyelitis leading to staphylococcal toxic shock syndrome in children

\begin{tabular}{|c|c|c|c|c|c|c|}
\hline Author & Year & Age, years/sex & Site of infection & Culture & Outcome & Toxin identified \\
\hline Aranow and Wood (9) & 1942 & 15/female & Left femur & Blood+ Pus+ & Discharged & Erythrogenic toxin \\
\hline \multirow[t]{2}{*}{ Milner et al (10) } & 1983 & 10/female & Right humerus & Blood+ Pus+ & Discharged & Phage 2 Enterotoxin B \\
\hline & & 7/female & Right tibia & Blood+ Pus+ & Discharged & Phage 2 Enterotoxin B \\
\hline Jacobson and Baltimore (11) & 1989 & 13/female & Left clavicle & Blood+ Pus+ & Discharged & Toxic shock syndrome toxin-1 \\
\hline
\end{tabular}

+ Positive

osteomyelitis in children, is typically observed among children seven to 14 years of age. It has a variable presentation including back, hip, thigh and/or buttock tenderness. The presentation may also include fever, decreased range of hip motion and refusal to weight bear. This variable presentation can lead to diagnostic delay. Plain films and bone scans may appear negative, while magnetic resonance imaging scans have a reported sensitivity of $97 \%$ (7).

There are scarce data regarding acute osteomyelitis presenting with staphylococcal TSS in children (8-11). A review of the English literature revealed four reported cases (Table 2). All four patients were girls between seven and 15 years of age. Also of note, all four cases involved the appendicular skeleton. Enterotoxin B was identified in two patients and TSST-1 was identified in one. Of note, the three toxins identified in our patient have not been previously described in osteomyelitis-associated TSS.

\section{REFERENCES}

1. Case definitions for infectious conditions under public health surveillance. Centers for Disease Control and Prevention. MMWR Recomm Rep 1997;46(RR-10):1-55.

2. Todd J, Fishaut M, Kapral F, et al. Toxic-shock syndrome associated with phage-group-I Staphylococci. Lancet 1978;2:1116-8.

3. Hajjeh RA, Perkins BA, Reingold A, et al. Toxic shock syndrome in the United States: Surveillance update, 1976-1996. Emerg Infect Dis 1999;5:807-10.

\section{CONCLUSION}

Osteomyelitis may be an occult cause for TSS in children. The variable presentation of pelvic osteomyelitis in children can lead to diagnostic delay, but should be considered in an older child who presents with hip, thigh or gluteal pain who may also be refusing to weight bear.

ACKNOWLEDGEMENTS: The authors thank the patient and her family for granting permission to present her case in this format.

INSTITUTION FROM WHICH WORK ORIGINATED: The Hospital for Sick Children, University of Toronto, Toronto, Ontario.

4. Adalat S, Dawson T, Hackett SJ, et al. In association with the British Paediatric Surveillance Unit. Toxic shock syndrome surveillance in UK children. Arch Dis Child 2014 May 1 [Epub ahead of print].

5. DeVries AS, Lesher L, Schlievert PM, et al. Staphylococcal toxic shock syndrome 2000-2006: Epidemiology, clinical features, and molecular characteristics. PLoS One 2011;6:e22997

6. Jarraud S, Cozon G, Vandenesch F, Bes M, Etienne J, Lina G. Involvement of enterotoxins $\mathrm{G}$ and I in staphylococcal toxic shock 
syndrome and staphylococcal scarlet fever. J Clin Microbiol 1999;37:2446-9

7. Faust SN, Clark J, Pallett A, Clarke NM. Managing bone and joint infection in children. Arch Dis Child 2012;97:545-53.

8. Chuang YY, Huang YC, Lin TY. Toxic shock syndrome in children: Epidemiology, pathogenesis, and management. Paediatr Drugs 2005;7:11-25.

9. Aranow H Jr, Wood W Jr. Staphylococcic infection simulating scarlet fever. JAMA 1942;119:1491-5.
10. Milner LS, de Jager J, Thomson PD, Doehring RO. Toxic shock syndrome caused by staphylococcal enterotoxin B. A report of 2 cases in children. S Afr Med J 1983;63:822-4.

11. Jacobson RM, Baltimore R. Toxic shock syndrome associated with osteomyelitis in premenarcheal girl. Pediatr Infect Dis J 1989;8:125-6. 


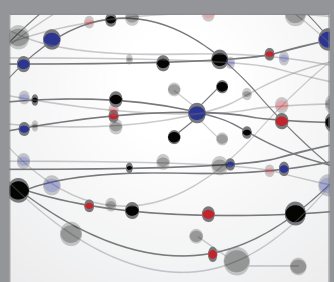

The Scientific World Journal
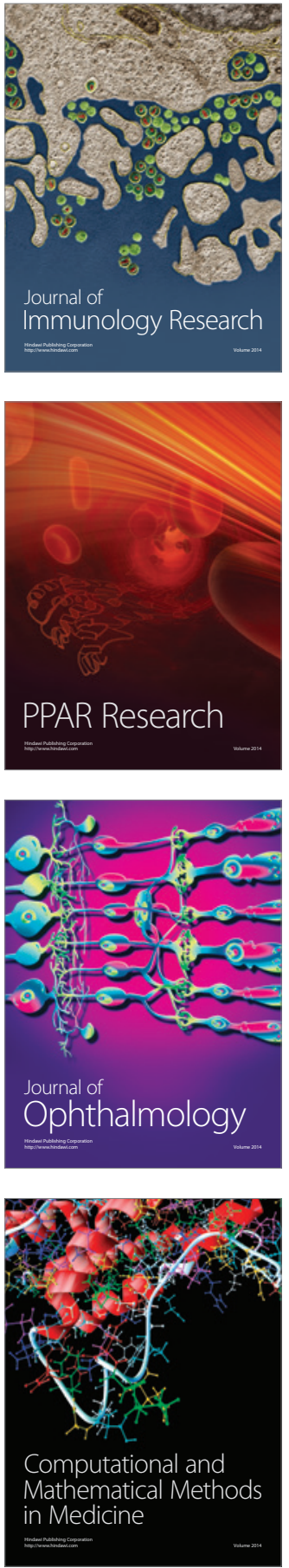

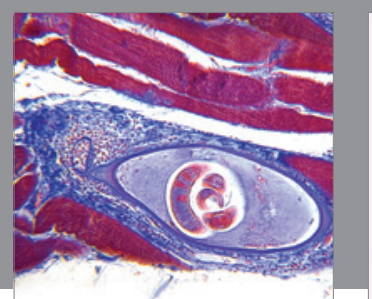

Gastroenterology Research and Practice

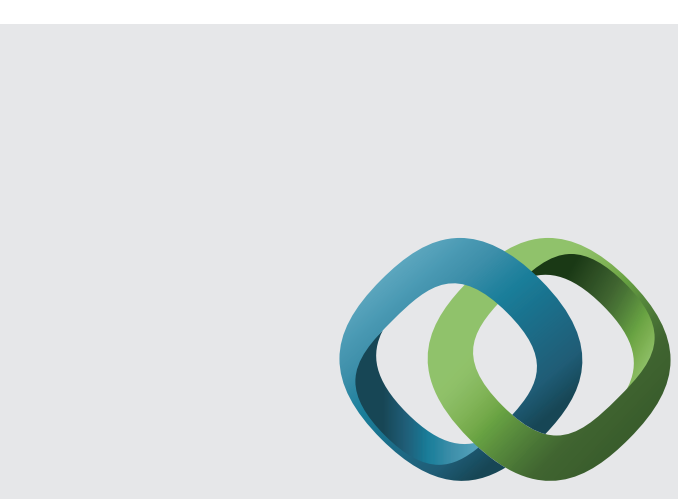

\section{Hindawi}

Submit your manuscripts at

http://www.hindawi.com
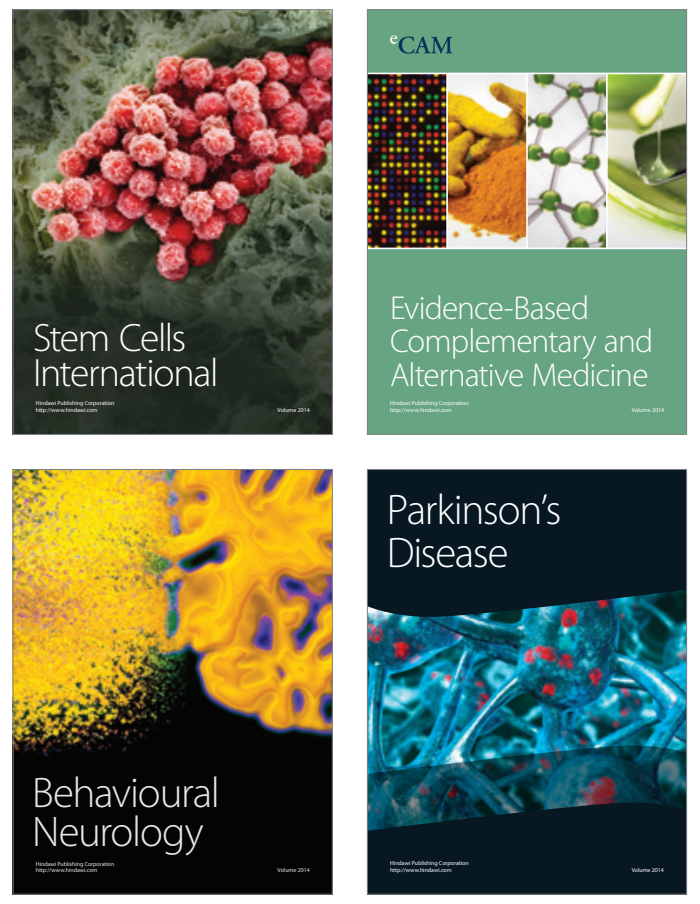
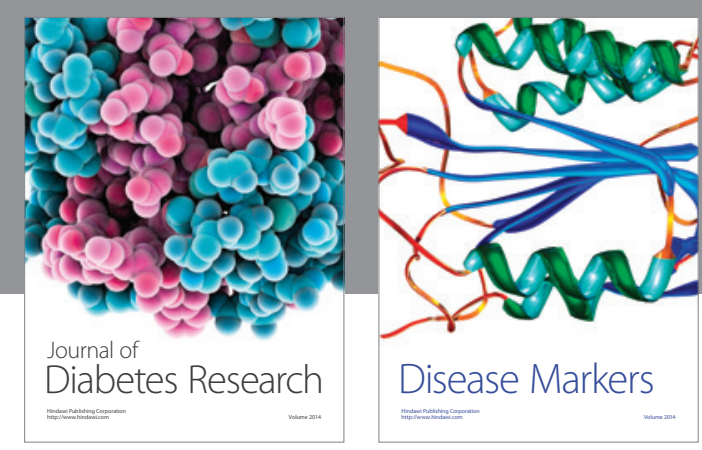

Disease Markers
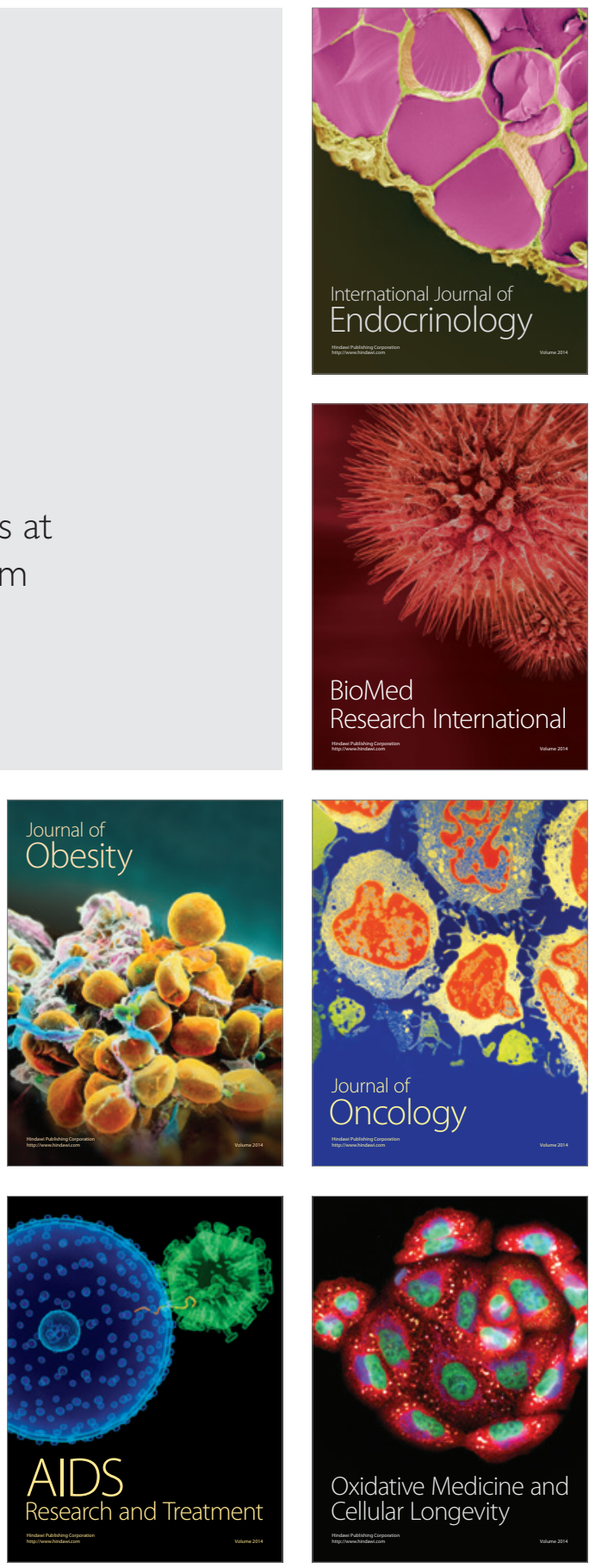